\title{
Correction to: Systematic Review of School-Wide Trauma-Informed Approaches
}

\section{Julie C. Avery ${ }^{1} \cdot$ Heather Morris $^{1} \cdot$ Emma Galvin $^{1} \cdot$ Marie Misso $^{1} \cdot$ Melissa Savaglio ${ }^{1} \cdot$ Helen Skouteris ${ }^{1,2}$}

Published online: 7 October 2020

(C) Springer Nature Switzerland AG 2020

\section{Correction to: Journal of Child \& Adolescent Trauma (321)} https://doi.org/10.1007/s40653-020-00321-1

Figure 1 contains incomplete texts. The correct one is shown below:

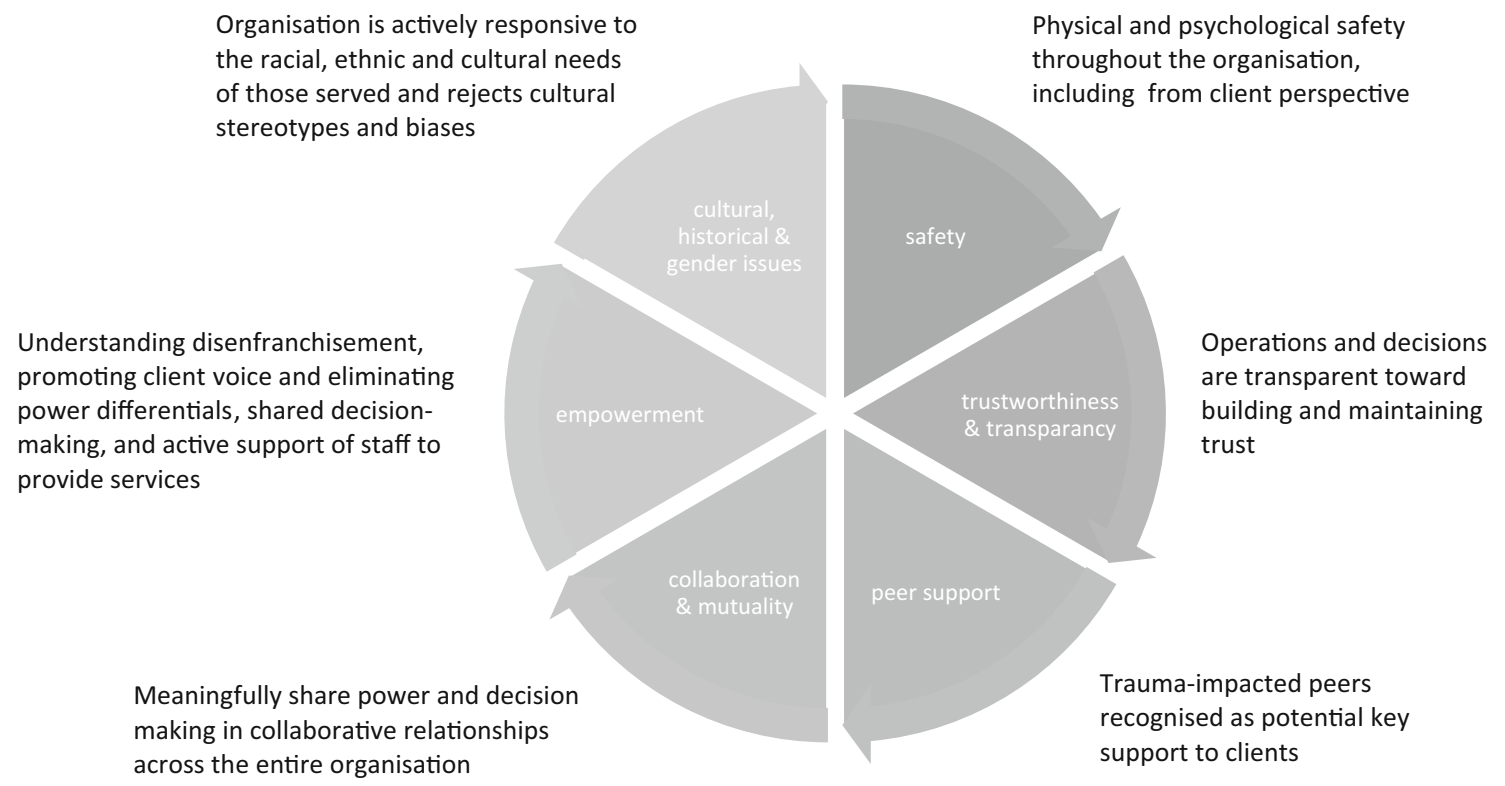

Fig. 1 Adapted from SAMHSA's six key principals of trauma-informed care

The online version of the original article can be found at https://doi.org/

Publisher's Note Springer Nature remains neutral with regard to juris$10.1007 / \mathrm{s} 40653-020-00321-1$ dictional claims in published maps and institutional affiliations.

Helen Skouteris

helen.skouteris@monash.edu

1 Monash Centre for Health Research and Implementation, School of Public Health and PreventiveMedicine, Monash University, Level 1, 43-52 Kanooka Grove Clayton; Locked Bag 29 Clayton Vic, Melbourne 3168, Australia

2 School of Business, Warwick University, Coventry, UK 